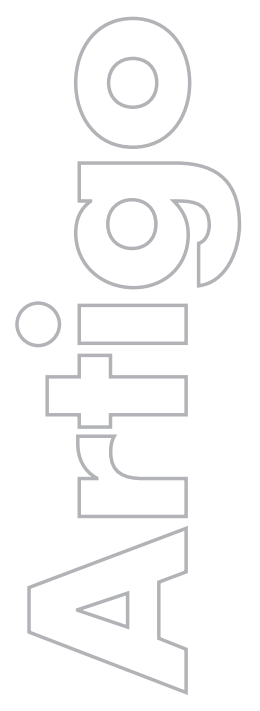

\title{
Arco Tietê: um território estratégico nos contornos entre o Estado e o mercado
}

\author{
Fernanda Pinheiro Silva
}

p. $97-114$

\section{revista}

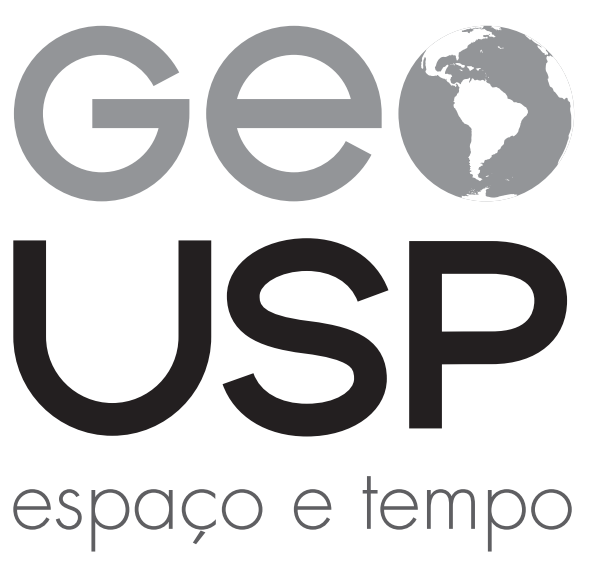

Volume $20 \bullet n^{\circ} 1(2016)$
Como citar:

SILVA, F. P. Arco Tietê: um território estratégico nos contornos entre o Estado e o mercado. Geousp - Espaço e Tempo (Online), v. 20, n. 1, p. 97-114, mês. 2016. ISSN 2179-0892.

Disponível em: http://www.revistas.usp.br/geousp/article/ view/90489. DOI: http://dx.doi.org/10.11606/issn.2179-0892. geousp.2016.90489.

\section{(c) $(1) \Theta$}

Este artigo está licenciado sob a Creative Commons Attribution 4.0 License. 


\section{Arco Tietê: um território estratégico nos contornos entre o Estado e o mercado}

\section{Resumo}

Analisando o espaço concebido como política de Estado, podem-se desvelar tendências importantes do processo de urbanização. Trata-se de uma forma de abordar projetos urbanísticos específicos, servindo de base para compreender como e por que determinados fragmentos do urbano se tornam alvos estratégicos da política do espaço e o que isso significa em termos da reprodução das relações (sociais) de produção. A partir dessa ressalva, segue-se uma tentativa de problematizarem a criação e o lançamento do território estratégico Arco Tietê como momento da reprodução crítica do capital, buscando sempre suas relações com a urbanização, também crítica, da cidade de São Paulo.

Palavras-chave: Reprodução crítica do capital. Produção do espaço. Urbanização. São Paulo. Arco Tietê.

\section{Arco Tietê: a strategic territory in the borders between the state and the market}

\section{Abstract}

When analyzing the space conceived as a state policy, one can reveal important trends of the urbanization process. This is a way to address specific urban projects, providing the basis for understanding how and why certain urban fragments become strategic targets of space policy and what this means for the reproduction of social relations of production.

In this research I attempt to discuss the Arco Tietê (Tietê Arch) strategic territory creation and launch as a moment of the critical reproduction of capital, trying to explain its relations with the critical urbanization of São Paulo.

Keywords: Critical reproduction of capital. Space production. Urbanization. São Paulo. Arco Tietê. 


\section{Introdução}

Desde seu lançamento, no início de 2013, ' o discurso que envolvia o território estratégico Arco Tietê anunciava que "terrenos fabris subutilizados" dariam lugar a novas áreas de moradia, que a ferrovia seria reformada e articulada com outros sistemas de transporte e que o rio Tietê e seus afluentes seriam recuperados para que pudessem se "reaproximar da cidade e de seus habitantes". Além disso, apresentado como etapa inicial para a consolidação do Arco do Futuro, ${ }^{2}$ abrangia uma área de urbanização antiga e consolidada da cidade de São Paulo e, portanto, estava pressuposto que para sua realização boa parte da materialidade edificada precisaria ser destruída para que em seu lugar fosse possível dar início à produção de novos usos.

No decorrer da análise que fizemos das duas fases em que se dividiu o processo convocado para estruturar um projeto que comportasse as demandas acima, surgiram questões acerca do papel que Estado e mercado desempenham no planejamento urbano e de como ambos se articulavam para dar cabo desta nova proposição de reestruturação urbanística. Assim, este artigo visa compartilhar algumas dessas questões e expor um caminho possível para pensar essa estratégia urbanística como momento da reprodução do capital, em especial no que toca ao modo como essa forma de reprodução social se liga à produção do espaço. ${ }^{3}$

\section{Arco Tietê: sentido e processo}

Em fevereiro de 2013, a Secretaria Municipal de Desenvolvimento Urbano (SMDU) iniciou uma parceria público-privada (PPP) para que consórcios, escritórios e/ou empresas apresentassem projetos viáveis para o que chamaram de território estratégico Arco Tietê, através de um Chamamento Público para Processo de Manifestação de Interesse (PMI). Já no anúncio do prazo para entrega final dos trabalhos, 60 dias após a publicação, o Arco recebeu críticas. Entre elas, destaca-se primeiramente a da arquiteta e urbanista Raquel Rolnik (2013), ponderando que "a publicação do edital pela prefeitura parece partir de uma manifestação clara de interesse por parte de uma empresa [Odebrecht] que já desenvolve um projeto semelhante em outra cidade [projeto Porto Maravilha no Rio de Janeiro]".

Fazendo uso de justificativas que também foram apresentadas em uma ação judicial que exigia a impugnação deste processo, ${ }^{4}$ a autora tornava público um primeiro estranhamento com relação ao Arco Tietê, afinal, como seria possível elaborar propostas para uma área de aproximadamente 6.000 hectares em apenas 60 dias? Quem teria condições de realizar tal proeza? A suposição imediata de Rolnik era a de que apenas grandes construtoras e escritórios de arquitetura ou corporações que contam com muitos funcionários seriam capazes de elaborar propostas desta magnitude com tanta rapidez. Ainda que o edital não exigisse que o

1 Trata-se de uma das primeiras medidas da recém-empossada (2013) administração da Prefeitura Municipal de São Paulo, comandada por Fernando Haddad, do Partido dos Trabalhadores (PT).

2 É importante pontuar que o Arco Tietê é parte de uma estratégia ampla, o Arco do Futuro, que, de acordo com a Prefeitura Municipal de São Paulo, "é um território estratégico para alterar o modelo de desenvolvimento urbano de São Paulo em direção a uma cidade mais equilibrada dos pontos de vista urbanístico, ambiental, econômico e social" (SMDU, 2014). O leitor pode consultar material sobre ambos os projetos no portal Gestão Urbana SP (Gestão Urbana, [s.d.]).

3 Este artigo resulta das pesquisas realizadas para minha dissertação de mestrado.

4 Gilberto Natalini, vereador pelo Partido Verde, entrou com um processo de improbidade administrativa exigindo o fim do Chamamento Público pela possível indução por interesses privados por parte da Odebrecht. 
participante se ocupasse da totalidade da área, a urbanista deixa claro no artigo que a complexidade urbanística que envolve as transformações da região da cidade exigiria mais tempo de pequenos escritórios ou mesmo de iniciativas populares.

Se tal pronunciamento não foi suficiente para revisões no processo, contribuiu, no entanto, para a ampliação dos prazos. As propostas, que seriam recebidas pela SMDU até meados de maio, passaram a ter como prazo final julho de 2013. Além de sugerir direcionamentos em um Chamamento Público, no mesmo artigo Rolnik apresenta um segundo e fundamental estranhamento com relação ao processo,

Na Faculdade de Arquitetura, na disciplina de Planejamento Urbano, nós ensinamos que primeiro se define o que se quer para a área, debatendo amplamente com a sociedade: ou seja, que cidade queremos? Qual é a transformação que desejamos para este lugar? Depois, uma vez definido o que se quer, discute-se quais são os melhores instrumentos para implementar a proposta. $\bigcirc$ caminho que está sendo colocado agora é o contrário, ele começa com o instrumento, que é a parceria público-privada. A partir daí se definirá o projeto. Mas se é parceria, a empresa tem que necessariamente ter lucro, e isso, claro, implica e compromete o projeto, na medida em que ele só ficará de pé se incluir a possibilidade de gerar grandes lucros imobiliários. A pergunta central, a partir disso, gira em torno da questão "qual é o uso mais rentável deste solo?" (Rolnik, 2013, p. X, grifos nossos).

Ancorada em sua experiência prática, teórica e política Rolnik afirmava que a execução do planejamento urbano deveria partir da definição dos objetivos de um plano para que depois fossem escolhidos os instrumentos que permitiriam alcançar tais objetivos. Pelo contrário, o Arco Tietê parecia inverter esse sentido, pois partia de um instrumento que atraísse investidores privados (a PPP) e só depois, e ao lado dos grandes interessados no mercado, definia a intenção e os objetivos do projeto.

Dando vazão às críticas ao processo iniciado pelo Arco Tietê, o também arquiteto e urbanista João Sette Whitaker Ferreira afirmou em seu blog que, com essa iniciativa, a Prefeitura Municipal de São Paulo (PMSP) delegava o poder de conceber, projetar e programar uma área da cidade às empresas privadas, afinal, "delegar o planejamento de uma área tão grande da cidade a empresas privadas é constatar que o Poder Público está, de alguma forma, renunciando a sua prerrogativa de fazer planejamento público" (Ferreira, 2013, p. X).

Com a abertura do edital para a primeira fase dessa PPP, nota-se que o Estado coloca à disposição do setor privado não só os mecanismos jurídicos, econômicos e urbanísticos, mas também poderes sobre a produção de uma concepção acerca da reestruturação urbanística e produtiva para São Paulo. Franqueavam-se a esse setor o planejamento urbanístico da área, a estruturação das normativas jurídico-urbanísticas, o planejamento econômico e social e a organização de mecanismos de participação e construção coletiva:

(A) Modelo urbanístico contendo hipóteses de transformação urbana [...]; (B) Modelagem jurídica apontando possíveis instrumentos ou processos que favoreçam a transformação, indução ou intervenção territorial; (C) Estudos socioeco- 
nômicos que demonstrem a promoção dos setores produtivos e a geração de emprego e renda [...]; (D) Meios de Interação Social e Institucional que contenham estratégias de construção coletiva da intervenção com a participação da absoluta maioria dos agentes envolvidos com este processo (São Paulo, 2013b, p. 4).

Percebe-se como prerrogativas do planejamento urbano nos termos de Ferreira (2013) e Rolnik (2013) foram postas à disposição das principais personificações ${ }^{5}$ dos negócios urbanos da capital paulista. ${ }^{6}$ Como consequência, é possível sugerir que o desenvolvimento do processo que envolve o Arco Tietê carrega consigo alterações na definição do papel que o Estado deve (ou não) cumprir no ato de planejar e intervir no urbano.

Ocupado com a noção de planejamento estratégico, Pedro Novais de Lima Jr. assinala, Como a definição de planejamento urbano é objeto de disputas [...], é delicado tomar uma definição como descritiva da prática do planejamento, pois cada uma diz respeito e reafirma a posição nesse espaço social daquele que a adota. Dito de outro modo, é necessário relativizar a definição de planejamento urbano justamente para escapar do confronto imediato advindo da luta de representações onde se visa ao monopólio da definição de planejamento (Lima Jr., 2003, p. 22).

Adotando os termos do autor, podemos considerar que uma definição do ato de planejar é, ao mesmo tempo, legitimação de uma prática social específica e negação de outras. Por sua vez, Rolnik e Ferreira assumem as seguintes práticas: ele deve ser público, as decisões sobre a cidade devem ser tomadas pelo Estado em constante diálogo com a sociedade civil, e seus objetivos precisam ser traçados antes da escolha dos instrumentos urbanísticos necessários para operacionalizá-los. Confrontada com o Arco Tietê, essa definição explicita uma disputa prática e teórica, pois, pautado sobretudo pelo acirramento das políticas neoliberais, como veremos adiante, o planejamento urbano evolvido nessa projeção aparece cada vez mais vinculado à noção de gerenciamento de cidades, cabendo ao Estado o papel de administrador.

É importante ressaltar que não fazemos uma defesa cega do Estado ou mesmo de sua soberania no planejamento urbano. A nosso ver, o Estado é "a garantia da mercadoria, da propriedade privada e dos vínculos jurídicos de exploração que jungem o capital e o trabalho" (Mascaro, 2013, p. 18) e, nesses termos, a forma estatal desponta como estrutura fundamental para a reprodução capitalista. A aparência de poder público, ou "terceiro termo" nas relações

5 Neste artigo, essa expressão tem o seguinte sentido: "Como portador consciente desse movimento, o possuidor do dinheiro torna-se capitalista. [...] ele funciona como capitalista ou capital personificado, dotado de vontade e consciência" (Marx, 1985a, p. 129).

6 Para mostrar o alcance desse comentário, seguem-se os 17 aprovados na primeira fase do processo relativo ao Arco Tietê: (1) Aecom, Blac, Carioca Engenharia, Cowan e CR Almeida, (2) ArcadisLogos, Mia Lehrer, Patrícia Akinaga, PWC, RTKL (Consultores: Azevedo Sette Advogados), (3) Axal Consultoria e Projetos Ltda., (4) Barbosa e Corbucci Arquitetos Associados Ltda., (5) Candido Malta Campos Filho associado a Fundação Centro Tecnológico de Hidráulica (FCTH), (6) Consórcio Triptyque (Triptyque Projetos Ltda., Argeplan, Phyrestore, Apur, NFU), (7) Construções e Comércio Camargo Corrêa S/A, (8) Construtora Odebrecht S/A e Construtora OAS S/A, (9) Construtoras Andrade Gutierrez S/A e Queiroz Galvão S/A, (10) Geométrica, Utc·constran, Escola da Cidade, (11) Grupo Impulso, (12) Idom Consultoria Ltda., (13) lurbi Arquitetos Associados, (14) Magalhães \& Associados, Figueroa Arquitetura e Urbanismo, Park Capital, (15) Planos Engenharia, Prof. Dr. Bruno Roberto Padovano e equipe e-DAU, (16) TC Urbes/ IBC e (17) Urbem - Instituto de Urbanismo e Estudos para a Metrópole. 
entre capital e trabalho, assume os conteúdos do que oculta: trata-se de um terceiro, mas fundamentalmente ligado à dominação do trabalho pelo capital. É o aparato estatal que garante a troca de mercadorias e a exploração da força de trabalho. Intermediado por instituições jurídicas e econômicas, é ele que estabelece a existência de mecanismos sociais que permitem a exploração, mas que, ao mesmo tempo, ocultam-na sob a forma do contrato.

Henri Lefebvre amplia o conceito de planejamento urbano através da noção de urbanismo, cujo sentido é "dominar e submeter à sua ordem o processo de urbanização" (2008a, p. 137). Assim, para o autor, mesmo que imbuído de boa vontade, de convicções políticas e que construído com participação popular, o sentido do urbanismo não pode ser deslocado da reprodução das relações (sociais) de produção e nem os urbanistas, ao exercer essa prática, podem se desligar de uma estratégia que "não só faz o espaço entrar na produção de mais-valia, ela visa uma reorganização completa da produção subordinada aos centros de informação e de decisão" (2008a, p. 141). A definição de um sistema (a cidade) cujos problemas podem ser identificados e resolvidos por meio de seus múltiplos subsistemas (transporte, saneamento, habitação etc.) é o que encerra o plano num caráter unitário e, portanto, lhe confere ilusões de classe.

Nas especificidades brasileiras, a defesa do planejamento estatal com vistas ao desenvolvimento social está ligada à luta por direitos sociais básicos tais como habitação, transporte, emprego e mesmo alimentação. Diferentemente da França encontrada por Lefebvre na passagem de 1960 para 1970, precisamos incorporar teoricamente uma realidade na qual ter acesso ao saneamento é um privilégio de classe. Nesse quadro, conquistar serviços públicos ganha um caráter radical, mas, ao mesmo tempo, cria ilusões de que essa conquista bastaria para pôr fim ao sentido crítico da sociedade capitalista.

Nessa perspectiva, embora reconheçamos sua importância no embate travado, não é possível assumir a definição de planejamento desses arquitetos. Tampouco poderíamos assumir uma definição neoliberal, naturalizando o gerenciamento empresarial de cidades. É nesse movimento do pensamento que a incorporação do conceito de urbanização crítica é fundamental para darmos continuidade ao texto, posto que ele expressa a "impossibilidade do urbano para todos, a não ser que se transformem radicalmente as bases da produção e da reprodução sociais" (Damiani, 2000, p. 30, grifo nosso).

De acordo com Damiani, é o negativo do urbano que o revela historicamente. Os pressupostos da urbanização estão na crise imanente de uma sociedade que se reproduz pelo trabatho, mas que o nega sistematicamente. Dessa perspectiva, planejamento e urbanismo revelam-se insuficientes para pôr fim às contradições colocadas pela reprodução crítica do capital; pelo contrário, surgem como forma de sobrevivência do capitalismo. Se a forma da centralidade é negada ao trabalhador, consequentemente, também lhe será negado o acesso aos benefícios de uma vida urbana. Se é na periferia da reprodução da vida que a massa trabalhadora, cada vez mais sem trabalho, luta para se reproduzir, caberá a ela, portanto, o espaço periférico.

Nos termos de uma urbanização crítica, consideram-se as desigualdades da sociedade brasileira, mas o planejamento estatista já não pode ser eleito como via de transformação. Quando as melhorias urbanas passam a fazer parte da realidade de um determinado fragmento de cidade, os imperativos da espoliação urbana também passam a vigorar sobre ele (Kowarick, 
1993). Porém, se o planejamento realizado pelo Estado não consegue ultrapassar as determinações da reprodução crítica do capital, atentar para deslocamentos na disputa por sua definição, sempre prática e teórica, pode explicitar aprofundamentos nas práticas de segregação socioespacial.

Sabe-se que o setor privado sempre esteve presente nos processos decisórios de planejamento urbano e que a reprodução da lógica do valor está entre os pressupostos de uma política urbana levada à frente pelo Estado, contudo, é o modo pelo qual a relação entre Estado e mercado se realiza que se transformou na centralidade desta investigação. Tal como sugere Ferreira (2013), acreditamos estar em curso a constituição de distinções qualitativas nessa parceria.

Do acompanhamento do território estratégico Arco Tietê surge um questionamento: estaríamos reconhecendo nele novos elementos constitutivos da relação entre Estado e mercado? Tratemos, antes, de apresentar os desdobramentos oficiais desse projeto.

\section{Apontamentos sobre o Arco Tietê}

Chamamento Público para o PMI foi dividido em duas fases, tendo como objetivo final a elaboração de propostas urbanísticas para o Arco Tietê com os devidos estudos de impacto e viabilidade. Na primeira fase, o Estado solicitou do setor privado a apresentação de propostas, gerais ou específicas, para o perímetro delimitado e, depois de compilar os projetos aprovados em um Relatório Resumo, convocou empresas e/ou consórcios ganhadores para elaborarem estudos de viabilidade dos projetos apresentados em uma segunda fase.

É importante destacar que a abertura de um PMI não implica abertura de processos licitatórios para execução de nenhuma das obras e/ ou intervenções apresentadas. Com respeito ao caso analisado, sua finalidade é única e exclusivamente a elaboração das projeções urbanísticas que passariam a compor o Arco Tietê em parceria com seus principais, possíveis e prováveis, investidores futuros.

Além disso, para participar do Chamamento, a instituição deveria arcar com todos os custos de seu trabalho tanto na primeira como na segunda fase. Estava claro que a PMSP só ressarciria empresas e consórcios cujos trabalhos fossem considerados viáveis, e o valor pago seria proporcional ao que dele fosse aproveitado pelo poder público. No fim da primeira fase, por exemplo, um valor de R\$2910 000,00 foi divido entre os 17 aprovados, sendo os maiores beneficiários Urbem (ressarcimento de R\$539.142,86), Consórcio Odebrecht/OAS (ressarcimento de $\mathrm{R} \$ 486.000,00)$, Consórcio Andrade Gutierrez/Queiroz Galvão (ressarcimento de $\mathrm{R} \$ 300.142,86)$, Idom (ressarcimento de $\mathrm{R} \$ 298.142,86$ ) e Camargo Corrêa (ressarcimento de $R \$ 240.142,86)$.

Para executar a primeira fase, empresas e consórcios tiveram como base um comunicado de Chamamento Público (São Paulo, 2013b), no qual constavam as intenções do Estado para transformação da área. Chama atenção o escasso detalhamento do documento, que na versão completa tinha oito páginas e não definia objetivos concretos, apenas "quatro setores prioritários para a elaboração dos estudos: (1) econômico, (2) ambiental, (3) mobilidade e acessibilidade; (4) habitacional"' (São Paulo, 2013b, p. 1-2). 
Além desse comunicado, a SMDU se responsabilizou pela elaboração de seminários para desenvolver temáticas específicas junto aos interessados. Nesses casos, embora o material apresentado tenha sido disponibilizado no site da Prefeitura, não se tratavam de eventos públicos. Examinando o material, nota-se foco na apresentação de instrumentais já existentes - como as proposições para revisão do Plano Diretor Estratégico e da lei de zoneamento - e na exposição de análises de órgãos específicos como da Empresa Paulista de Planejamento Metropolitano (Emplasa), da Companhia de Saneamento Básico do Estado de São Paulo (Sabesp) e de Secretarias específicas como a de Transporte, do Verde e Meio Ambiente e de Habitação, além da participação da Fundação Sistema Estadual de Análise de Dados (Seade).

O prazo para recebimento das propostas da primeira fase terminou em 24 de junho de 2013. No total, 26 instituições privadas apresentaram suas próprias projeções para o Arco Tietê, das quais, 17 foram considerados "tecnicamente viáveis" (total ou parcialmente). Analisando todas as propostas vitoriosas, encontramos dois pontos em comum. $\bigcirc$ primeiro deles é o suporte ideológico: a valorização da natureza chega aos rios. Se o rio Tietê era tido como um dos maiores entraves para o desenvolvimento urbano e social de São Paulo, agora ele passa a ser tratado como elemento central de um novo contexto social. $\bigcirc$ rio como "singularidade" em todos os 17 projetos é o que justifica uma nova programação da vida urbana e da cidade. segundo ponto diz respeito a uma forma específica de operacionalização: todos os projetos apresentam a necessidade de novas PPP e concessões, em todas as suas variações. ${ }^{7}$

Interpretadas e sobrepostas por uma equipe de técnicos da Prefeitura especificamente formada para o trabalho, essas propostas consolidaram o Relatório Resumo para os Estudos de Viabilidade (Relatório Resumo), que "é o documento que subsidia a elaboração deste escopo detalhado e orienta o desenvolvimento da segunda fase" (São Paulo, 2013a, p. 6).

Trata-se do apontamento oficial que passaria a discriminar setores, instrumentos urbanísticos possíveis, obras desejadas, fases de operacionalização, entre tantas outras determinações do Arco Tietê. Destaca-se todavia que, mesmo sendo elaborado pelo Estado, o Relatório Resumo é fruto da compilação de propostas apresentadas por representantes dos negócios urbanos (construtoras, escritórios de arquitetura, incorporadoras), portanto, não deve ser confundido com Termos de Referência ou outros tipos de projetos urbanísticos estatistas que subsidiam licitações e concursos. Ao invés de lidar com representações de espaço concebidas pelo Estado, trata-se de um documento que foi fruto da junção de intervenções projetadas pelo capital privado e gerenciadas pelo Estado.

Em sintonia com o novo Plano Diretor Estratégico de São Paulo de 2014, o Relatório Resumo define o território estratégico Arco Tietê a partir de três Projetos de Intervenção Urbana (PIU): dois Apoios Urbanos, com vistas à urbanização e promoção de infraestrutura nas duas margens do rio Tietê, e o Centralidade, que pretende criar um núcleo de atividades de escala metropolitana nas proximidades do Anhembi. Destaca-se que os PIU são instrumentos destinados ao ordenamento e reestruturação da Macroárea de Estruturação Metropolitana (na qual está inserido o Arco Tietê), e neles são permitidas quatro diferentes modelagens urbanísticas: Operações Urbanas Consorciadas, Concessões Urbanísticas, Áreas de Intervenção Urbana e Áreas de Estruturação Local.

7 As Concessões estão dentro do escopo da lei das PPP e podem variar entre patrocinadas, administrativas e na versão Concessão Urbanística. 
Com relação aos Apoios Urbanos, o relatório especifica dois projetos distintos, o Apoio Urbano Norte (AUN) e o Apoio Urbano Sul (AUS). A projeção do AUN abrange a várzea expandida ao norte do rio Tietê. Sua intenção: "criação de uma nova centralidade para usos de comércio, serviços e empresas, como indústrias de base tecnológica” (São Paulo, 2013a, p. 8). As principais obras anunciadas: enterramento da linha de alta tensão da AES Eletropaulo e da Companhia de Transmissão de Energia Elétrica de São Paulo; conexão entre as rodovias Anhanguera-Bandeirantes com a Dutra-Fernão Dias através da construção de uma via-bulevar; e criação de uma "infovia", com implementação, por exemplo, de cabos de fibra ótica.

○ AUS foi projetado para a região ao sul do rio Tietê visando "ao melhor aproveitamento do solo urbano, à modernização do sistema de transportes de alta capacidade de passageiros, à minimização do impacto do transporte de cargas por trilhos e à qualificação da paisagem urbana ao longo deste percurso" (São Paulo, 2013a, p. 10). As principais obras: transposição e/ ou enterramento de parte da malha ferroviária; requalificação e extensão das avenidas Marquês de São Vicente e Ermano Marchetti; produção de uma "qualidade urbanística diferenciada", fomentando projetos habitacionais; e reestruturação do Elevado Costa e Silva, com sua possível demolição a longo prazo.

São projeções ambiciosas que, segundo a PMSP:

[... está necessariamente articulada a produção de novas frentes de expansão da ocupação urbana e a reorganização do sistema fundiário do Arco, o que possibilita o acesso à terra para a promoção de concessões e parcerias para a produção de habitação social, equipamentos públicos e infraestrutura para o desenvolvimento econômico da cidade (São Paulo, 2013a, p. 8, grifo nosso).

Passemos para o projeto da Centralidade. Este propõe "o desenvolvimento de uma centralidade de abrangência metropolitana [...] viabilizada através de uma proposta de transformação de uso do solo e ocupação do solo urbano com o aproveitamento de terras públicas" (São Paulo, 2013a, p. 13). Suas propostas apontam para a criação de equipamentos âncoras (possivelmente um Centro de Gerenciamento Territorial da Metrópole) para implantação de empresas de tecnologia através de PPP a curto prazo, de transformações no Campo de Marte a médio prazo, e rebaixamento da via expressa da Marginal Tietê (total ou parcial) e edificação de um porto fluvial a longo prazo.

Não seria viável abordar todos os Projetos Específicos e Programas de Desenvolvimento. Contudo, a evocação constante da necessidade de conceder áreas e serviços para investidores privados se mantém como pilar em quase todas as proposições. Associado a estas concessões, o Relatório Resumo também anuncia uma possibilidade de flexibilização da legislação urbanística.

Os projetos urbanísticos e de engenharia que eventualmente sejam aplicados aos estudos deverão estar adequados à legislação vigente, bem como às normas técnicas aplicáveis a cada área do projeto. Em caso de propostas excepcionais, poderão ser recepcionados minutas para projetos de lei e normas específicas ao atendimento destes objetivos (São Paulo, 2013a, p. 35, grifos nossos). 
A breve descrição das duas fases do Arco Tietê e, em especial, o modo pelo qual o Estado constrói o projeto executivo que demanda estudos de viabilidade e coloca a legislação urbanística à disposição de proponentes que, como visto, personificam grandes capitais vinculados ao setor imobiliário.

\section{Dos fundamentos da análise}

Julgamos que no trato do espaço concebido como política de Estado podem-se desvelar tendências importantes do processo de urbanização e, sendo uma maneira de reflexão sobre projetos urbanísticos específicos, isso pode servir de base para entender como e por que determinados fragmentos do urbano tornam-se alvos estratégicos da política do espaço. Assim, iniciamos uma tentativa de compreender o território estratégico Arco Tietê no interior da reprodução crítica do capital, especificamente no que a conecta com a urbanização de São Paulo. Antes, porém, é preciso deixar claro o que entendemos por reprodução crítica do capital e, consequentemente, como ela se desdobra num entendimento específico da urbanização.

$\bigcirc$ sentido e finalidade do movimento do capital é a valorização do valor. $\bigcirc$ mundo da valorização, também apreendido como processo de modernização, tem sua universalidade formal estabelecida pela lógica da mercadoria. Afinal, "o capital não é uma coisa, mas determinada relação de produção, social, pertencente a determinada formação sócio-histórica que se representa numa coisa" (Marx, 1986, p. 269), ou seja, a própria mercadoria.

O ciclo do capital está ancorado em um processo produtivo específico, o modo de produção capitalista, cujo motor reside na contradição capital-trabalho. A exploração do trabalho pelo capital para a produção de mercadorias constitui, assim, o fundamento de uma sociedade moderna que, engendrada por relações sociais de produção capitalista, precisa realizar sistematicamente os movimentos de produção, distribuição, circulação e consumo.

Marx encontrou a condição material para o estabelecimento da contradição capital-trabalho na instituição da propriedade privada capitalista, cujo desdobramento fundamental é a separação entre o trabalho e os meios de produção. Se no interior do processo produtivo a relação capital-trabalho opera através da oposição entre trabalho morto (capital constante) e trabalho vivo (capital variável), socialmente ela se revela no confronto direto entre diferentes classes sociais. É o tempo de trabalho socialmente necessário para a produção de determinada mercadoria que configura o conteúdo de seu valor, assim, se o capital explora o trabalho é porque apenas este último tem a capacidade de valorizá-lo, ou seja, é a exploração da força de trabalho (extração de mais-valia) que permite ao capital realizar seu sentido e finalidade.

Do encadeamento deste processo destaca-se o trabalho, transformado na mercadoria força de trabalho, como única fonte de valor, e a contradição capital-trabalho como uma relação social de exploração entre classes.

Para o capital é necessário repor a todo momento a produção de mercadorias, assim, sua produção deve ser necessariamente reprodução. Em seu movimento vital de busca constante pela valorização do valor, o aumento da composição orgânica de capital ${ }^{8}$ surge como

8 A composição orgânica do capital (composição-valor do capital) pode ser entendida como medida da relação entre capital constante (forças produtivas) e capital variável (força de trabalho). A composição orgânica de capital será tanto maior quanto maior for o quantum de capital constante em relação ao de variável (Marx, 1985b, p. 187-259). 
tendência global. $\bigcirc$ desenvolvimento das forças produtivas aparece, assim, como tendência global no interior de uma corrida pelo aumento da produtividade do capital, pois nele existe uma possibilidade de aumentar a intensidade da exploração do trabalho.

[... ] não basta de modo algum, para produzir mais-valia mediante a transformação do trabalho necessário em mais-trabalho, que o capital se apodere do processo de trabalho em sua forma historicamente herdada ou já existente, e apenas alongue sua duração. Tem de revolucionar as condições técnicas e sociais do processo de trabalho, portanto, o próprio modo de produção, a fim de aumentar a força produtiva do trabalho, mediante o aumento da força produtiva do trabalho reduzir o valor da força de trabalho, e assim encurtar parte da jornada de trabalho necessária para a reprodução deste valor (Marx, 1985a, p. 251)

Contraditoriamente, Marx explicita neste processo uma dimensão crítica e estrutural do capital. Se "O valor das mercadorias está na razão inversa da força produtiva" (Marx, 1985a, p. 253), ao passo que cresce o capital constante em relação ao capital variável, elucida-se também uma tendência do capital de expulsar a força de trabalho do processo produtivo, ou seja, de eliminar de sua reprodução social a única substância que tem a capacidade de valorizar o valor, o trabalho vivo.

Ainda que em termos absolutos a taxa de mais-valia possa crescer em decorrência da intensificação da exploração do trabalho, a degeneração da taxa de lucro (mais-valia calculada sobre o capital global) como tendência da reprodução social aponta para a redução da capacidade de valorizar o valor,

[...] à medida que a taxa de valorização do capital global, a taxa de lucro, é o aguilhão da produção capitalista (assim como a valorização do capital é sua única finalidade), sua queda retarda a formação de novos capitais autônomos, e assim aparece como ameaça para o desenvolvimento do processo de produção capitalista; ela promove superprodução, especulação, crises, capital supérfluo, ao lado de população supérflua (Marx, 1986, p. 183).

Em outras palavras, na reprodução do capital residem determinações críticas de sua destituição. Porém, se o sentido da queda tendencial da taxa de lucro é a diminuição relativa do trabalho vivo em relação ao trabalho morto, ela também demarca o aumento da produtividade do trabalho e o crescimento da massa de valores. Por desse desdobramento, Marx (1986, p. 167) mostra que "o processo de produção capitalista é essencialmente, ao mesmo tempo, processo de acumulação". Além disso, como momento da produção capitalista, a acumulação consistiria sempre na tentativa de conjugar excedentes momentâneos de capital e de trabalho (Marx, 1986, p. 167-168), e as crises aparecem como "soluções momentâneas violentas das contradições existentes" (Marx, 1986, p. 188).

Partindo dos fundamentos críticos do capital, David Harvey recupera, a partir de uma releitura da obra de Rosa Luxemburgo, um aspecto imprescindível para a sobrevivência do capitalismo: a reposição constante do processo de expropriação. Tal como assinala, os impactos 
da crise de sobreacumulação do capital exigem a liberação de ativos a custos reduzidos, seja de capital ou trabalho, e isso só se realiza concretamente através de processos que remontam ao que foi chamado por Marx de acumulação primitiva .

No capítulo XV do Livro Terceiro de O capital, Marx (1986) já havia chamado atenção para essa distinção. Embora o sentido seja o mesmo - repor constantemente a separação entre os trabalhadores e os meios de produção - a formação e acumulação de capital exige três movimentos distintos,

[... inaugura-se com a acumulação primitiva (Livro Primeiro. Cap. XXIV), aparece depois como processo constante na acumulação e concentração de capitais e por fim se expressa aqui como centralização de capitais já existentes em poucas mãos e como descapitalização de muitos (nisso é que agora se transforma a expropriação). Esse processo levaria em breve a produção capitalista ao colapso, se tendências contrárias não atuassem constantemente, com efeito descentralizador, ao lado da força centrípeta (Marx, 1986, p. 186)

Com o objetivo de renovar o debate e destacar que se trata de um processo em constante reposição, Harvey atualiza o conceito de acumulação primitiva pelo de acumulação por espoliação, encontrando neste argumento uma chave para compreender a importância que processos de reestruturação urbanística passam a ter na reprodução social.

As crises são reveladas como crises de sobreacumulação e, através delas, evidencia-se a impossibilidade de conjugar sistematicamente "excedentes de capital (em termos de mercadoria, moeda e capacidade produtiva) e excedentes de força de trabalho" (Harvey, 2013, p. 78). Por este caminho, o autor destaca o que, em sua visão, atuaria como a principal estratégia capaz de promover a absorção desses capitais e, portanto, de evitar a desvalorização absoluta do capital,

A expansão geográfica e a reorganização espacial proporcionam tal opção. [...] Como a expansão geográfica com frequência envolve investimentos em infraestruturas físicas e sociais de longa duração, a produção e reconfiguração das relações espaciais oferecem um forte meio de atenuar, se não de resolver, a tendência à formação de crises no capitalismo (Harvey, 2013, p. 78, grifo nosso).

De acordo com Harvey, é neste processo que a urbanização se articula estruturalmente com o desenvolvimento de uma sociedade capitalista a fim de garantir a continuação de sua reprodução ampliada.

A produção do espaço em geral e da urbanização em particular tornou-se um grande negócio no capitalismo. É um dos principais meios de absorver o excesso de capital. Uma proporção significativa da força de trabalho é empregada na construção e manutenção do ambiente edificado. Grandes quantidades de capitais associados, geralmente mobilizados sob a forma de empréstimos a longo prazo, são postos em movimento no processo de desenvolvimento urbano (Harvey, 2011, p. 137). 
Relacionando importantes momentos críticos da absorção de excedentes com ocasiões emblemáticas de ampliação da escala da urbanização, o autor estabelece um nexo lógico e histórico entre urbanização, acumulação de capital e formação de crises. Como afirma, a crise europeia de 1848 foi atenuada pela reestruturação da cidade de Paris entre 1852 e 1870, a crise do pós-Segunda Guerra Mundial foi suavizada pela suburbanização dos EUA e a crise fiscal da década de 1970, cuja expressão mais emblemática foi a falência da cidade de Nova York em 1975, foi amortecida pelo fato de que "cada área urbana do mundo teve seu boom na construção em meio a uma enxurrada de imigrantes pobres que, simultaneamente, criaram um planeta favela" (Harvey, 2011, p. 142).

Destaca-se, contudo, que a ampliação escalar do processo de urbanização não muda seu fundamento. Mesmo que atue num primeiro momento em sentido contrário às crises de sobreacumulação, esse processo não deve ser concebido como solução para os termos críticos da reprodução social, pois sua realização depende de investimentos que, "alimentados pelo endividamento, tornam-se o epicentro de formação de crises" (Harvey, 2011, p. 137), conectando essa estratégia de combate às crises com a promoção de novas crises.

Nesses termos, a magnitude e o alcance do Arco Tietê nos permitiriam refletir sobre os imperativos da ampliação da escala do processo de urbanização, revelando o Estado como ente social capaz de conduzir tal façanha. $\bigcirc$ movimento crítico de reprodução social vincula o ímpeto planejador, interventor, financiador e assegurador do Estado com sua capacidade única de engendrar a produção de um espaço que vislumbre a universalização da forma mercadoria, pois, como ressaltado anteriormente, seu principal objetivo é manter o regime de acumulação, o que o torna "a garantia da mercadoria, da propriedade privada e dos vínculos jurídicos de exploração que jungem o capital e o trabalho" (Mascaro, 2013, p. 18).

Reforçando a presença do Estado e seu protagonismo no projeto analisado aqui, demarcamos que mudanças na gestão e operacionalização das políticas urbanas podem revelar meandros do modo pelo qual se realiza o movimento desenvolvido por Harvey. Desse ponto de vista, selada pelos vínculos entre setor público e privado, a relação entre Estado e mercado aparece como possibilidade analítica para problematizar uma dupla segurança. De um lado, o Estado aspirando a reduzir os riscos de que seus investimentos e projeções não sejam seguidos pela entrada massiva do capital privado. De outro, o mercado e as personificações dos negócios urbanos exigindo garantias de rentabilidade superiores à média para investimentos de longo prazo. Assim, o trajeto sugerido atrela a análise do Arco Tietê às parcerias público-privadas e ao modo pelo qual elas se tornaram instrumentos fundamentais da política urbana.

\section{Parceria público-privada}

Se até o final dos anos 1970 nota-se certa centralização do urbanismo dentro da burocracia estatal, sobrevém um momento de transição, no qual o Estado passa a delegar seus poderes de planejador aos imperativos do mercado. $O$ poder público e sua tecnocracia eram diretamente responsáveis pelo urbanismo no Brasil, e o modernismo, com suas influências funcionalistas, dominava a prática do planejamento urbano (Villaça, 2010). Todavia, em especial no decorrer dos anos 1980, a expansão neoliberal pós-Consenso de Washington, fruto 
da intensificação da crise de excedentes do capitalismo mundial, introduz um novo modelo de urbanismo no país (e no mundo), reconhecido pelo emprego de termos como planejamento estratégico e marketing de cidades (Harvey, 2011; 2013).

Dessa perspectiva, a dependência de parcerias entre Estado e capital privado para operacionalizar o planejamento urbano não é novidade, nem para a política urbana do país, nem para a da cidade de São Paulo. Implementado no Brasil a partir de experiências no Rio de Janeiro (Lima Jr., 2003), esse modelo de planejamento se consolidou principalmente através de Operações Urbanas que visam operacionalizar grandes transformações na cidade e, ao mesmo tempo, concedem ao capital privado o direito de: driblar leis de uso e ocupação do solo; se apropriar privadamente de investimentos públicos através do monopólio da propriedade; produzir espaços que materializassem suas representações - competitivas, segregadas e que buscam rentabilidade para grandes fluxos de capital. Ou seja, o território estratégico ganha vida com a abertura de um território livre para a acumulação de capitais.

No artigo intitulado A fórmula mágica da parceria, Mariana Fix aborda as Operações Urbanas Consorciadas (OUC) como,

[... "modernas" formas de parceria, que tomam como justificativa a crise fiscal, diante da qual o Estado não teria mais condições de financiar as obras urbanas, devendo, portanto, assumir forçosamente apenas o papel de "promotor" (ou "indutor" e "regulador"), e criar condições para facilitar a instalação de infraestrutura pela própria iniciativa privada (Fix, 2003, p. 10).

Ao criar uma moeda de troca para a compra de potencial construtivo adicional através dos Certificados de Potencial Adicional de Construção (CEPAC), ${ }^{9}$ a OUC torna possível a sua comercialização diretamente no mercado financeiro. Uma parceria entre poder público e capital privado é então estabelecida. Nos termos da reprodução crítica do capital, este instrumento consegue ampliar o rendimento dos empreendimentos ao incorporar a certeza de ganhos provenientes de investimentos públicos na área, visto que a execução de obras públicas é garantida pelo próprio Estado, que promulga uma lei que o obriga a investir todo o dinheiro arrecadado do setor privado exatamente no local em que ele concentrou seu capital.

Ao tratar de outro instrumento urbanístico, a Concessão Urbanística, Ricardo Baitz nos permite aprofundar a questão,

A rigor, as Operações Urbanas não constituem Parcerias Público-Privadas, pois é o poder público que se encarrega da promoção da obra que dinamiza a região. Contudo, o espírito incitador da economia previsto nas PPPs já se faz interiorizado nas Operações Urbanas, e a Concessão Urbanística o externaliza (Baitz, 2011, p. 210-211).

Nessa passagem, Baitz assinala uma distinção fundamental entre ambas. Embora a OUC já incorpore o "espírito incitador" das PPP, ela não o realiza completamente. No caso das

9 Cepac são título financeiros regulados e fiscalizados pela Comissão de Valores Mobiliários cujo preço depende das movimentações na Bolsa de Valores. No que toca às movimentações urbanísticas, sua compra pode ser usada para alterar o uso do solo ou construir acima do potencial construtivo permitido. 
concessões, a viabilidade é dada pela conquista, por parte do setor privado, de direitos exclusivos do Estado (desapropriar terrenos e cobrar tributos pelo seu uso, por exemplo).

Em sentido amplo, as parcerias público-privadas indicam toda e qualquer forma de acordo firmado entre administração pública e particulares, para a realização de atividades de interesse público. Contudo, conforme a Lei Federal n 11079/04 que regula esta modalidade de contrato, a PPP é sempre um mecanismo de concessão, seja ela patrocinada ou administrativa. Concordando com o autor, vemos na tentativa de implementação de uma Concessão Urbanística as marcas de uma transformação que caminha em direção à transferência do direito de desapropriar terrenos.

É em função desta distinção que Baitz consegue enxergar neste processo novos elementos do momento crítico da reprodução do capital. Ao sugerir que "há a possibilidade do capital invertido em edificações não se valorizar acima das médias", o autor situa a OUC e a Concessão Urbanística como "instrumentos e políticas que assegurem uma rentabilidade superior ao circuito financeiro" (Baitz, 2011, p. 214). Os riscos são minimizados em função do poder que esses instrumentos transmitem ao setor privado e no caso específico da Concessão Urbanística até mesmo a desapropriação de proprietários privados passa a ser possível, o que oferece plenos poderes sobre a propriedade da terra no local do projeto.

Em conferência, o fundador do Instituto Urbem, ${ }^{10}$ Philip Young, assinalou a importância das PPP para a transformação contemporânea das cidades, visto que de seu ponto de vista, elas constituem a única maneira possível de fomentar o desenvolvimento urbano na fase atual do capitalismo. Para Young, o maior problema dos projetos urbanísticos, sobretudo na região central de cidades como São Paulo, é o preço da terra, e, como os custos de construção podem ser facilmente rebatidos, o limite de risco que os empreendedores podem aceitar para investir nessas regiões é a garantia da propriedade da terra. Em resumo, para o presidente de uma das empresas que participam do PMI para o Arco Tietê, cabe ao Estado a concessão de terrenos e ao setor privado, a responsabilidade de levantar e usufruir economicamente da área.

A fala de Young reforça os argumentos de Baitz (2011). Vinculado ao mercado financeiro, o setor imobiliário procura empreendimentos que o remunerem rapidamente. Contudo, como a inversão de capital no ambiente construído é um processo de remuneração a longo prazo, para investir é preciso ter cada vez mais o controle de riscos. É neste momento que a Concessão Urbanística surge como possibilidade de segurança, pois, acessando a propriedade da terra através da concessão de terrenos, e não de sua compra, o capital inicial e os riscos de um retorno insuficiente do investimento diminuem.

Circunscrito nesse processo, o Arco Tietê pode apontar uma de suas franjas. Se as formas conhecidas de parceria entre Estado e setor privado, como afirma Mariana Fix (2003, p. 11) a respeito da OUC, "funciona como um mecanismo para que apenas uma fração da cidade continue a resolver seus problemas, utilizando o Estado como instrumento privado de acumulação", ou, como descreve Ricardo Baitz acerca das Concessões Urbanísticas, expressam a segurança dos investimentos ao "permitirem por um lado uma série de lucros extraordinários e por outro lado, assegurarem uma inversão contínua de capital” (2011, p. 214).

10 Conferência realizada em maio de 2013, pela Faculdade de Arquitetura e Urbanismo da USP. Destaca-se aqui o fato de o Urbem ser uma das entidades que participam da PPP para o Arco Tietê. 
Ao tratar o planejamento estratégico como "imagem fenomênica" de um momento da "ideologia tecnocrática eficaz", Amélia Damiani nos permite revisitar a história da relação entre Estado e urbanismo a partir da "busca perfeita de adequação":

No interior da produção do espaço, negativamente, e consumindo a vivência, coloca-se a história idealista da teoria do espaço como ideologia tecnocrática eficaz. $\bigcirc$ espaço é, ao mesmo tempo, reafirmado como abrigo de conteúdos, perfeitamente ajustados ou ajustáveis, como busca da perfeita adequação. $\bigcirc$ planejamento estratégico é sua imagem fenomênica (Damiani, 2008, p. 210).

Se em um dado período histórico, no Brasil até meados de 1980, a eficácia e o funcionalismo urbano estiveram no centro do pensamento estatista, desde a década de 1990, o Estado se aproxima da gestão empresarial. No desenvolvimento do Arco nos deparamos com uma nova qualidade desta relação. Nesses termos, sugerimos que o Arco Tietê aprofunda a operacionalização do que conhecemos por planejamento estratégico.

Muito antes do lançamento do Arco Tietê, a arquiteta Marilena Fajersztajn, técnica responsável pelas Operações Urbanas do município, já havia destacado em entrevistall algumas inovações em curso nos mecanismos estatais para a "promoção" de transformações urbanas. Como assinalou, uma vez que "Cada uma [OUC] vai corrigindo equívocos da outra", "Agora, o que está se pensando, e é a primeira vez que se faz isso [em relação às OUC Mooca-Vila Carioca, Rio Verde-Jacu Pêssego e Lapa-Brás], é você contratar estudos urbanísticos de profissionais selecionados por licitações".

Fajersztajn também deu destaque para o fato da prefeitura ser muito criticada pelas operações em vigência, que na visão de muitos dão conta somente de planos viários e de habitação, sempre com escasso detalhamento do desenho urbanístico. Na expectativa de reverter este quadro, em 2010, a PMSP abre licitações para contratar empresas e/ou consórcios que, após apresentar propostas com o devido detalhamento do desenho urbanístico e dos estudos de viabilidade, seriam responsáveis pelo acompanhamento, gestão e operacionalização do projeto final de três novas OUC: a Mooca-Vila Carioca, a Rio Verde-Jacu Pêssego e a Lapa-Brás.

$\bigcirc$ Arco Tietê, portanto, não inova ao designar que a modelagem urbanística para transformação de uma área específica da cidade seria produzida por um consórcio privado, neste ponto ele apenas segue a nova tendência do setor público paulistano. Mantendo e ampliando os domínios territoriais de uma dessas operações (OUC Lapa-Brás), o Arco também incorpora as atualizações que esta operação inseria na planificação estatal.

Por outro lado, Fajersztajn deixou claro na entrevista que, "como prefeitura, ela sabe identificar as carências que a área tem", portanto, era a SMDU - técnicos de carreira e nomeados pela gestão vigente - que estabelecia os objetivos e as principais intervenções de uma OUC através de Termos de Referência que representam planos de intervenções urbanas produzidos pelo Estado. Nesse sentido, mesmo "terceirizando" a elaboração de estudos e modelagens urbanísticas, ao definir objetivos e prever intervenções, o Estado se mantém como responsável pelo planejamento urbano da área. Até então, ainda era o poder público que decidia e produzia as novas representações de um espaço concebido, delegando ao setor privado apenas a elaboração do desenho urbanístico.

11 Entrevista concedida em outubro de 2012, na Secretaria Municipal de Desenvolvimento Urbano. 
Pelo contrário, o Arco Tietê e sua operacionalização revelam um processo no qual o município encarrega o capital privado de decisões sobre o planejamento urbano de São Paulo. Além disso, diferentemente da Concessão Urbanística, pela qual o município desenvolve um projeto executivo e habilita os interessados a implementá-lo por meio das PPP (Baitz, 2011), o Arco as incorpora já na elaboração de seu projeto executivo.

\section{Considerações finais}

Longe de esgotar o assunto, procuramos expor um caminho possível para compreender os desdobramentos do Arco Tietê. Trata-se do desafio de articular a investigação de um processo burocrático e institucional que inova a operacionalização do planejamento urbano com uma compreensão materialista histórica que incorpora o urbano e sua produção. Além disso, é importante destacar que, até o momento em que se escreve este artigo, os resultados da segunda fase do Chamamento Público não haviam sido divulgados pela PMSP, fato que nos permite situar esta projeção num momento específico da produção de um espaço concebido (representação de espaço), mas de alcance limitado quanto a sua realização.

Inicialmente, o Arco Tietê é entendido como aprofundamento de uma prática específica do urbanismo reconhecida como planejamento estratégico, na qual a política caminha em direção à economia e o papel Estado se aproxima da gestão empresarial:

Propondo alternativas para o enfrentamento da realidade descrita, o planejamento estratégico constitui, de fato, elemento fundamental para que a representação se objetive, na forma de programas e projetos diversos, na canalização de recursos públicos para determinadas prioridades e na instauração de processos decisórios que privilegiem e autorizem a visão dos capitalistas e experts (Lima Jr., 2003, p. 231).

Por fim, seus desdobramentos surgiram como expressão de um momento no qual o Estado engendra estratégias refinadas de gerenciamento e passa a exigir garantias de que será seguido pelos investidores ao abrir novos campos para negócios que envolvem o urbano. Para mobilizar o ciclo do capital por meio da urbanização, as projeções urbanísticas devem ser seguidas pelo interesse do capital, tornando-se concretas direta ou indiretamente. ${ }^{12}$ Tal como as OUC e as Concessões Urbanísticas permitiram revelar um Estado que se preocupa com a segurança de investimentos privados, o Arco Tietê permite perceber a permanência dessa necessidade de controlar o risco dos investidores privados. Contudo, é possível acrescentar a presença de um Estado que não pode correr o risco de abrir um território de livre para acumulação sem a garantia de que será seguido por esses mesmos investidores.

Nesses termos, desvia-se de uma crítica aparentemente ligada aos governos para uma crítica ao Estado como fundamento da reprodução do capital. O Arco Tietê aparece como realização de um momento da reprodução social no qual o setor público precisa criar mecanis-

12 Com essa ressalva, chamamos atenção para a representação de espaço como parte do processo de expropriação. Mesmo que não se realize objetivamente como intervenção ou obra, encontramos nela um potencial para efetivar diferentes planos de segregação socioespacial. Destaca-se que esta breve reflexão anuncia um debate caro à dissertação de mestrado que origina este artigo (Silva, 2015). 
mos institucionais a fim de que o setor privado indique exatamente o que e como deve seguir a urbanização, para só então iniciar a abertura de territórios que libertem entraves urbanísticos para a acumulação através do espaço. Nele, as PPP deixam de ser usadas apenas na licitação de obras e serviços, como já o são nas OUC, ou na entrega de porções da cidade, como no caso das Concessões Urbanísticas, para se transformar em apoios fundamentais para a elaboração de projetos, passando a valer como instrumentos para a produção direta de novas representações do espaço. A nosso ver, esse é um caminho analítico indicado pelos termos em que se opera o Chamamento Público aqui analisado e essa é a radicalidade da relação entre Estado e mercado que se pode encontrar nos desdobramentos de um território estratégico.

\section{Referências}

BAITZ, R. Uma aventura pelos elementos formais da Propriedade: nas tramas da relativização, mobilidade e abstração, à procura da contra-propriedade. Tese (Doutorado em Geografia Humana) - Faculdade de Filosofia, Letras e Ciências Humanas, Universidade de São Paulo, São Paulo, 2011.

DAMIANI, A. L. Espaço e geografia - observações de método: elementos da obra de Henri Lefebvre e a geografia. Tese (Livre-docência em Geografia Humana) - Faculdade de Filosofia, Letras e Ciências Humanas, Universidade de São Paulo, São Paulo, 2008.

A. L. A metrópole e a indústria. Terra Livre, n. 15, p. 21-37, São Paulo, 2000.

FERREIRA, J. S. W. Que futuro para o arco do futuro? Cidades para que $(m)$ ? (online), São Paulo, 25 fev. 2013. Disponível em: <http://cidadesparaquem.org/blog/2013/2/25/que-futuro-para-o-arco-do-futuro>. Acesso em: 2 out. 2013.

FIX, M. A fórmula mágica da parceria: Operações Urbanas em São Paulo. Cadernos de Urbanismo, 2003. Disponível em: <http://scholar.google.com.br/scholar?q=mariana+fixEb $\mathrm{tnG}=\varepsilon \mathrm{hl}=$ pt-BREas_sdt=0\%2C5\#6>. Acesso em: 10 mar. 2014.

GESTÃO URBANA SP. Portal da Prefeitura Municipal de São Paulo, [s.d.]. Disponível em: $<$ http://gestaourbanasp.org/>. Acesso em: 11 mar. 2014.

HARVEY, D. O novo imperialismo. São Paulo: Boitempo, 2013.

O enigma do capital. São Paulo: Boitempo, 2011.

KOWARICK, L. A espoliação urbana. São Paulo: Paz e Terra, 1993.

LEFEBVRE, H. A revolução urbana. Minas Gerais: Editora UFMG, 2008a.

. Espaço e política. Minas Gerais: Editora UFMG, $2008 \mathrm{~b}$.

LIMA JR., P. N. Uma estratégia chamada "planejamento estratégico". Tese (Doutorado em Planejamento Urbano e Regional) - Instituto de Pesquisa e Planejamento Urbano e Regional, Universidade Federal do Rio de Janeiro, Rio de Janeiro, 2003.

MARX, K. O Capital: crítica da economia política, Livro Terceiro. Tomo IV. São Paulo: Nova Cultural, 1986. 
O Capital: crítica da economia política, Livro Primeiro. Tomo I. São Paulo: Nova Cultural, 1985a.

. O Capital: crítica da economia política, Livro Primeiro. Tomo II. São Paulo: Nova Cultural, $1985 \mathrm{~b}$.

MASCARO, A. Estado e forma política. São Paulo: Boitempo, 2013.

ROLNIK, R. Arco do Futuro: começando mal? Blog da Raquel Rolnik, São Paulo. 15 fev. 2013. Disponível em: <http://raquelrolnik.wordpress.com/2013/02/15/arco-do-futuro-comecando-mal/>. Acesso em: 12 mar. 2013.

SÃO PAULO (Cidade). Relatório Resumo (2013). Comunicado de Chamamento Público $n$. 1/2013/SMDU: Relatório resumo para os estudos de viabilidade. São Paulo: Secretaria Municipal de Desenvolvimento Urbano, set. 2013a.

. Chamamento Público (2013). Comunicado de Chamamento Público n. l/2013/SMDU. São Paulo: Secretaria Municipal de Desenvolvimento Urbano, fev. $2013 b$.

SMDU. SECRETARIA MUNICIPAL DE DESENVOLVIMENTO URBANO. Portal da prefeitura da cidade de São Paulo, 2014. Disponível em: <http://www.prefeitura.sp.gov. $\mathrm{br} /$ cidade/secretarias/desenvolvimento_urbano/>. Acesso em: 11 mar. 2014.

SILVA, F. P. A urbanização e o movimento de regulação do urbano: uma análise crítica das transformações da várzea do rio Tietê. Dissertação (Mestrado em Geografia). Faculdade de Filosofia, Letras e Ciências Humanas, Universidade de São Paulo, São Paulo, 2015.

VILLAÇA, F. Uma contribuição para a história do planejamento urbano no Brasil. In: DEÁK, C.; SCHIFFER, S. (Org.). O processo de urbanização no Brasil. São Paulo: Edusp, 2010. p. 169-243. 